\title{
Convulsions Associated with the Use of a Synthetic Cannabinoid Product
}

\author{
Aaron B. Schneir • Todd Baumbacher
}

Published online: 13 December 2011

(C) American College of Medical Toxicology 2011

\begin{abstract}
Introduction Clinical presentations following the use of various "spice" or synthetic cannabinoids have included agitation, anxiety, emesis, hallucinations, psychosis, tachycardia, and unresponsiveness. Convulsions were described in a one report although there was not laboratory confirmation for synthetic cannabinoids. In another published report laboratory confirmation for a synthetic cannabinoid was done in which the patient manifested activity that was interpreted as a possible convulsion.

Case Report We describe a patient who had two witnessed generalized convulsions soon after smoking a "spice" product that we later confirmed to have four different synthetic cannabinoids.

Discussion Convulsions have only rarely been associated with marijuana exposures. Recreational use of synthetic cannabinoids is a very recent phenomenon and there is a very limited, albeit burgeoning, literature detailing the associated complications including convulsions we have reported here. The absence of anticonvulsant phytocannabinoids in spice products could potentially be one of multiple unknown mechanisms contributing to convulsions.
\end{abstract}

Keywords Cannabinoids · Spice · Convulsions · JWH . AM-2201

\footnotetext{
A. B. Schneir $(\triangle)$

Division of Medical Toxicology, Department of Emergency Medicine, University of California, San Diego Medical Center, 200 West Arbor Drive \#8925,

San Diego, CA 92103, USA

e-mail: aschneir@ucsd.edu

T. Baumbacher

Department of Emergency Medicine, University of California, San Diego Medical Center,

San Diego, CA, USA
}

\section{Introduction}

The recreational use of synthetic cannabinoids is a very recent phenomenon [1]. A small but rapidly growing body of literature has detailed various adverse effects which prompted the US Drug Enforcement Agency to recently designate five synthetic cannabinoids as schedule I substances [2]. Clinical presentations following the use of various "spice" or synthetic cannabinoids have included agitation [3-6], anxiety [3-5, 7, 8], emesis [3, 9], hallucinations $[4,5]$, psychosis $[6,10]$, tachycardia [3-8], and unresponsiveness [6]. Convulsions have been described in one published report, although there was not laboratory confirmation for the presence of synthetic cannabinoids [3]. Another report, in which there was laboratory confirmation for metabolites of the synthetic cannabinoid JWH-018, a patient was interpreted by the authors as having had a possible convulsion [6]. Convulsions associated with recreational use of Cannabis sativa (marijuana) use appear to be exceptionally unusual [11-13]. We describe a patient who had two witnessed generalized convulsions soon after smoking a "spice" product that we later confirmed to have four different synthetic cannabinoids.

\section{Case Report}

A 19-year-old male in his normal state of health had a witnessed generalized 1 to 2-min convulsion while smoking a product "Happy Tiger Incense." He had no history of convulsions nor was he on any medications. The product label described it as being "JWH-018 free" and that it was "not for human consumption." The contents of the package appeared to be plant material. Paramedics arrived to find a slightly confused patient. During transport to the emergency 
department (ED), the patient vomited and soon afterward had a second generalized convulsion that was treated with $5 \mathrm{mg}$ of intranasal midazolam. The patient arrived to the ED slightly sedate and confused, both of which rapidly resolved. He denied the use of any drugs except for the recreational use that day of the spice product. Initial vital signs were: pulse, 84 beats per minute; respirations, 18 cycles per minute; temperature, $36.4^{\circ} \mathrm{C}$; and blood pressure 177/82 $\mathrm{mmHg}$. Physical examination, complete blood count, chemistries (including sodium and calcium), and TSH were normal. An electrocardiogram was normal including no QRS nor QT interval prolongation. A urine drug of abuse screen was positive for benzodiazepines as a class, and negative for amphetamines as a class, barbiturates, opiates, and benzoylecgonine (cocaine metabolite). A computed tomography scan of the brain was normal. A lumbar puncture revealed normal cerebrospinal fluid parameters (cells, glucose, protein, negative gram stain). The patient remained asymptomatic and without any intervention, his repeat blood pressure was $123 / 68 \mathrm{mmHg}$. He was discharged after a short observation. A urine sample collected on the day of presentation was later analyzed by Millenium Laboratories (San Diego, CA, USA) and further excluded the presence of carisoprodol (and metabolite meprobamate), ethanol, methylenedioxymethamphetamine, phencyclidine, tramadol (and metabolite tapentadol), meperidine (and metabolite normeperidine), methadone, propoxyphene (and metabolite norpropoxyphene), $\Delta$-ninetetrahydrocannabinoid, and tricyclic antidepressants. Additionally, a benzodiazepine screen excluded the presence of alpha-hdroxyalprazolam, 7-amino-clonazepam, lorazepam, nordiazepam, temazepam, and oxazepam. The remains of the product smoked were sent to NMS labs (Willow Grove, PA, USA) for analysis. Four synthetic cannabinoids (JWH018, JWH-081, JWH-250, and AM-2201) were identified. Quantitative analysis was not performed.

\section{Discussion}

We describe a patient who had two witnessed generalized convulsions soon after smoking a "spice" product that we later confirmed to contain four synthetic cannabinoids. In a prior published report, a convulsion was described $1 \mathrm{~h}$ after use of a product SpicyXXX, and although a drug screen was reported to be negative, there was no testing of the product nor the patient to confirm the presence of synthetic cannabinoids [3]. Another report, in which there was laboratory confirmation for metabolites of the synthetic cannabinoid JWH-018, a patient is described having two episodes during which "his eyes crossed and he was flailing his arms" that the authors interpreted as a possible convulsion [6]. Although four different synthetic cannabinoids were found in the product our patient used, and laboratory testing done on the patient excluded many other potential drug-related etiologies, we cannot exclude the possibility that another compound that we did not test for may have contributed. Additionally, we do not know which, if not all, of the various synthetic cannabinoids may have been responsible. The absence of $\Delta$-ninetetrahydrocannabinoid $(\Delta-9-\mathrm{THC})$ in the patient's urine excluded recent marijuana use and is not inconsistent with the use of synthetic cannabinoids, the vast vajority of whom have structures distinct from THC. On March 1, 2011, the US Drug Enforcement Administration designated as schedule I substances (high potential for abuse, no accepted medical use, lack of accepted safety) five synthetic cannabinoids (JWH-018, JWH-073, JWH-200, CP-47,497, and cannabicyclohexanol) [2]. The patient described in our report acquired the product subsequent to this designation and despite its label of being "JWH-018 free," JWH-018 was in fact present, as were three other synthetic cannabinoids, none of which are currently schedule I substances.

Despite how prevalent the recreational use of marijuana is both currently and historically in various societies, convulsions associated with use have only been described very rarely [11-13]. Convulsions have occasionally been described in children after accidental ingestions [14, 15]. Abuse of the synthetic cannabinoids appears to have only begun in the middle to latter part of the last decade [1] and there is currently a very limited, albeit burgeoning, literature detailing the associated complications including convulsions we have reported here [3-10, 16].

The mechanism(s) responsible for synthetic cannabinoidinduced convulsions is currently unknown as is whether certain synthetics or combinations thereof will be implicated. The cannabinoid composition found in spice products significantly differs from those found in marijuana and may be relevant regarding the occurrence of convulsions. When extensively tested, spice products have been found to have one or multiple synthetic cannabinoids, but as expected, not co-existant phytocannabinoids [17]. The phytocannabinoids in marijuana include the major psychoactive component, $\Delta$-9-THC [18], and various non-psychoactive cannabinoids including cannabinol, cannibidiol, and $\Delta$-9-tetrahydrocannabivarin (THCV) [19, 20]. Although animal studies have provided conflicting results (proconvulsant and anticonvulsant) on the effect of $\Delta$-9-THC depending on the model used [12], cannabidiol and its derivatives has been found to be consistently anticonvulsant in animal models [12, 21, 22] and in limited human trials $[23,24] . \Delta-9-\mathrm{THCV}$ was also recently demonstrated to exert anticonvulsant properties [20]. Although we did not specifically exclude the presence of the anticonvulsant phytocannabinoids in the product used 
by our patient, the confirmed absence of $\Delta$-9-THCwould make their presence seem extremely unlikely. It is intriguing to consider how the absence of the anticonvulsant phytocannabinoids in spice products may contribute to the frequency and mechanism of convulsions associated with synthetic cannabinoids. However, this is only one of the multiple potential unknown mechanisms that will only be answered by future studies.

\section{References}

1. Vardakou I, Pistos C, Spiliopoulou C (2010) Spice drug as a new trend: mode of action, identification and legislation. Toxicol Lett 197:157-162

2. United States Drug Enforcement Administration. Chemicals used in "Spice" and "K2" type products now under federal control and regulation. Available at http://www.justice.gov/dea/pubs/pressrel/ pr030111.html. Accessed on May 4, 2011.

3. Simmons JR, Skinner CG, Williams J, Kang CS, Schwartz MD, Wills BK (2011) Intoxication from smoking "spice". Ann Emerg Med 57:187-188, letter

4. Banerji S, Deutsch CM, Bronstein AC (2010) Spice ain't so nice: [abstract]. Clin Toxicol 48:632

5. Bebarta VS, Varney S, Sessions D et al (2010) Spice: a new "legal" herbal mixture abused by young active duty military personnel: [abstract]. Clin Toxicol 48:632

6. Simmons J, Cookman L, Kang C, Skinner C (2011) Three caes of "spice" exposure. Clin Toxicol 49:431-433

7. Schneir AB, Cullen J, Ly BT (2011) "Spice" girls: synthetic cannabinoid intoxication. J Emerg Med 40:296-299

8. Vearrier D, Osterhoudt KC (2010) A teenager with agitation. Pediatr Emerg Care 26(6):462-464

9. Canning JC, Ruha A-M, Pierce R, Torrey M, Reinhart SJ (2010) Severe gi distress after smoking JWH-018: [abstract]. Clin Toxicol 48:618

10. Muller H, Sperling W, Kohrmann M et al (2010) The synthetic cannabinoid spice as a trigger for an acute exacerbation of cannabis induced recurrent psychotic episodes. Schizophr Res 118:309-310

11. Ng SK, Brust JC, Hauser WA, Susser M (1990) Illicit drug use and the risk of new-onset seizures. Am J Epidemiol 132:47-57

12. Gordon E, Devinsky O (2001) Alcohol and marijuana: effects on epilepsy and use by patients with epilepsy. Epilepsia 42:12661272

13. Keeler MH, Reifler CB (1967) Grand mal convulsions subsequent to marijuana use. Case report. Dis Nerv Syst 28:474-475

14. Bonkowsky JL, Sarco D, Pomeroy SL (2005) Ataxia and shaking in a 2-year-old girl: acute marijuana intoxication presenting as seizure. Pediatr Emerg Care 21(8):527-528

15. Spadari M, Glaizal M, Tichadou L, Blanc I, Drouet G, Aymard I, De Haro L, Hayek-Lanthois M, Arditti J (2009) Accidental cannabis poisoning in children: experience of the Marseille poison center. Presse Med 38(11):1563-1567

16. Every-Palmer S (2011) Synthetic cannabinoid JWH-018 and psychosis: an explorative study. Drug Alcohol Depend 117:152-157

17. Dresen S, Ferreiros N, Putz M, Westphal F, Zimmerman R, Auwarter V (2010) Monitoring of herbal mixtures potentially containing synthetic cannabinoids as psychoactive compounds. J Mass Spectrom 45:1186-1194

18. Howlett AC, Breivogel CS, Childers SR, DEADwyler SA, Hampson RE, Porrino LJ (2004) Cannabinoid physiology and pharmacology: 30 years of progress. Neuropharmacology 47:345-358

19. Seely KA, Pratheer PL, James LP, Moran JH (2011) Marijuanabased drugs: innovative therapeutics or designer drugs of abuse? Mol Interv 11:36-51

20. Hill AJ, Weston SE, Jones NA, Smith I, Bevan SA, Williamson EM, Stephens GJ, Williams CM, Whalley BJ (2010) $\Delta-9$ Tetrahydrocannabivarin suppresses in vitro epileptiform and in vivo seizure activity in adult rats. Epilepsia 51:1522-1532

21. Karler R, Turkanis SA (1981) The cannabinoids as potential antiepileptics. J Clin Pharmacol 21:437S-448S

22. Consroe P, Martin A, Singh V (1981) Antiepileptic potential of cannabidiol analogs. J Clin Pharmacol 21:428S-436S

23. Cunha JM, Carlini EA, Pereira AE, Ramos OL, Pimentel C, Gagliardi R, Sanvito WL, Lander N, Mechoulam R (1980) Chronic administration of cannabidiol to healthy volunteers and epileptic patients. Pharmacology 21:175-185

24. Carlini EA, Cunha JM (1981) Hypnotic and antiepileptic effects of cannabidiol. J Clin Pharmacol 21:417S-427S 